\title{
ARASTIRMA RESEARCH
}

\section{Uzaktan Eğitim Alan Üniversite Öğrencilerinin Sosyal Kaygı Düzeylerinin Belirlenmesi Determination of Social Anxiety Levels of Distance Education University Students}

\author{
Reyhan Eskiyurt 1D, Erdinç Alaca 1 iD
}

\section{öz}

Covid-19 pandemisinin dünya çapında hızlı bir şekilde yayılması sonucunda yaşamın tüm alanları etkilenmiş olup sosyal medya platformları, sözsüz ipuçlarının varlığı açısından yeni bir tür sosyal durum yaratmaktadır. Sosyal etkileşim ve izolasyondaki olası değişiklikler göz önüne alındığında, sosyal kaygı ile ilişkili duygular pandemi sırasında etkilenebilmektedir. Bu çalışma uzaktan eğitim alan üniversite öğrencilerinin sosyal kaygı düzeylerini belirlemek amacıyla yürütülmüştür. Çalışmaya 2020-2021 eğitim öğretim yılında uzaktan eğitim alan 670 üniversite öğrencisi katılmışır. Çalısma verileri Liebowitz Sosyal Kaygı Ölçeği (LSKÖ) ve Olumsuz

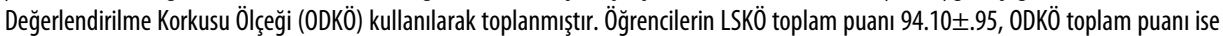
$30.38 \pm 9.07$ bulunmuştur. Öğrencilerin en çok kaygı yaşadığı sosyal durumlar: önceden hazırlanmaksızın bir toplantıda kalkıp konuşmak, seyirci önünde hareket, gösteri ya da konuşma yapmak, dikkatleri üzerinde toplamak, bir gruba önceden hazırlanmış sözlü bilgi sunmak olarak bulunmuştur. Öğrencilerin çevrim içi eğitimi olumsuz değerlendirme korkusuyla baş etmek için güvenlik sağlayıcı bir ortam olarak değerlendirdikleri sonucuna ulaşıımışır. Bu durum sosyal kaygılı bireyin kaygı düzeyinin artmasına ve yüz yüze eğitime geçildiğinde sınıf ortamında meydana gelebilecek olan gerçek sosyal durumlarda zorlukların yaşanmasına yol açabilir. Sosyal kaygısı olan öğrencilerin pandemi sürecinde çevrim içi sosyal durumlara maruziyetlerinin artırılması önerilmektedir.

Anahtar sözcükler: Sosyal kaygı, uzaktan eğitim, üniversite öğrencileri, pandemi

\section{Abstract}

The rapid spread of the Covid-19 pandemic worldwide has affected all areas of life. Social media platforms create a new kind of social situation in terms of the presence of nonverbal cues. Emotions associated with social anxiety can be affected during the pandemic, due to possible changes in social interaction and isolation. This study was conducted to determine the social anxiety levels of university students receiving distance education. 670 university students who receiving distance education in the 2020-2021 academic year participated in the study. Study data were collected using the Liebowitz Social Anxiety Inventory (LSAS) and The Brief Fear of Negative Evaluation Scale (BFNE). The total score of the students' LSAS was $94.10 \pm .95$, and the total score of BFNE was $30.38 \pm 9.07$. The social situations in which the students experienced the most anxiety were speaking up at a meeting without prior preparation, acting, performing, or speaking in front of an audience, being the center of attention, giving a prepared oral talk to a group. It was concluded that the students considered online education as a safe environment to cope with the fear of negative evaluation. This situation can lead to an increase in the anxiety level of the socially anxious individual and to experience difficulties in real social situations that may occur in the classroom environment when face-to-face education is started. It is recommended to increase the exposure of students with social anxiety to online social situations during the pandemic process.

Keywords: Social anxiety, distance education, university students, pandemic

${ }^{1}$ Ankara Yıldırım Beyazıt Üniversitesi, Ankara

$\triangle$ Reyhan Eskiyurt, Ankara Yıldırım Beyazıt Üniversitesi, Sağlık Bilimleri Fakültesi, Hemşirelik Bölümü, Ankara, Turkey reyhan.ryhn.reyhan@gmail.com | 0000-0003-0421-4914

Geliş tarihi/Received: 20.08.2021 | Kabul tarihi/Accepted: 15.09.2021 |Çevrimiçi yayın/Published online: 26.12.2021 
COVID-19 (SARS-CoV-2) pandemisinin dünya çapında hızlı bir şekilde yayılması sonucunda yaşamın tüm alanları etkilenmiş olup çevrim içi iletişim, sosyal hayatın ayrılmaz bir parçası haline gelmiştir (Khalil ve ark. 2020). Ekrana dayalı iletişim sağlayan sosyal medya platformları, sözsüz ipuçlarının varlı̆̆ı açısından yeni bir tür sosyal durum yaratmaktadır (Walther 2011, Valkenburg ve ark. 2016). COVID-19 nedeniyle sosyal etkileşim ve izolasyondaki olası değişiklikler göz önüne alındığında, sosyal kaygı ile ilişkili duyguların pandemi sırasında etkilenebileceği belirtilmektedir (Thompson ve ark. 2021). Sosyal kayg1 utanmanın meydana gelebileceği, korkunun veya kaygının gerçek tehditle orantılı olmadığı bir veya daha fazla sosyal durumun sürekli korkusu olarak tanımlanmaktadır (Clark ve Beck 2010, Hofmann ve DiBartolo 2010). Kayg1 başkalarının inceleme ve olumsuz değerlendirmeleri sonucunda utanç, aşağılanma ve mahcup olma duygularına yol açacak olan korkudan kaynaklanmaktadır (Türkçapar 2018).

Salgın hastalıkların yüksek düzeyde kaygı ile ilişkili olduğu bulunmuştur. Örneğin, ağır akut solunum yolu sendromu (SARS) salgını birçok ülkede sosyal problemler ve kaygiya neden olmuştur (Rubin ve ark. 2009, Zheng ve ark. 2020). Yapılan bir araştırma, COVID-19 pandemisinden önce depresyon geçiren kişilerin pandeminin başlangıcından sonra daha şiddetli semptomlar yaşadığını göstermiştir (Groarke ve ark. 2020). Çok sayıda çalışma pandemilerin neden olduğu sosyal kaygısı incelemiştir (Liberman ve Trope 2014, Kim 2019, Zheng ve ark. 2020). Çevrim içi sosyal durumlar ve sosyal kaygıyı inceleyen çalışmalarda sosyal kaygının, belirsiz çevrim içi sosyal durumların olumsuz yorumlarıla ilişkili olduğu (Kingsbury ve Coplan 2016, Carruthers ve ark. 2019), çevrim içi durumlarda sosyal baskının azaldığı ve sosyal kaygıllı bireylerin daha rahat hissetikleri belirtilmektedir (Weidman ve ark. 2012).

COVID-19 pandemisinin başlamasından sonra, sosyal kaygı semptomlarının arttığı, yalnızlı̆̆ın kötüleştiği, bireylerin aile ve arkadaşlarıyla olan iletişimlerinin azaldığı bulunmuştur (Thompson ve ark. 2021). Okulların kapanması ve uzaktan eğitime geçilmesiyle, öğrencilerin akranlarılla ve öğretmenleriyle olan iletişimi sınıllanmıştır (Courtney ve ark. 2020). Okullar kapalıyken kayg1 uyandiran etkenlere maruz kalınmadığı için sosyal kaygıyla ilgili sıkıntılarda geçici bir azalmanın gözlemlenebileceği belirtilmektedir (Loades ve ark. 2020). Pandemi sürecinde alınan tedbirler nedeniyle, sosyal kaygısı olan kişiler psikolojik tedavinin maruz kalmayı teşvik edeceği çoğu durumlardan, kaçınarak olumlu pekiştirme almaktadırlar (Morris ve Ale 2011). Buna ek olarak, kaçınma olumsuz pekiştirme yoluyla daha fazla kaçınmayı doğurarak sosyal kaygılı bireyler için okullar yeniden açıldığında akut dengesizlik olabileceği belirtilmektedir (Morrissette 2021).

Pandemi sürecinde uzaktan eğitim alan üniversite öğrencileriyle yapılan çalı̧malar incelendiğinde, sosyal kayg1 semptomlarını destekler nitelikte sonuçlara ulaşıldığı görülmektedir (Pop ve ark. 2011, Adnan ve Kainat 2020, Karakuş ve ark. 2020, Sindiani ve ark. 2020, Wang ve Zhao 2020). Wang ve Zhao'nın (2020) çalışmasında, çevrim içi öğrenme ile bağlantılı olarak üniversite öğrencilerinin kaygıları incelenmiştir. Üniversite öğrencilerinin genel popülasyona göre daha yüksek düzeyde kaygıya sahip olduğu, tıp öğrencilerinin ve kız öğrencilerin daha fazla kaygı gösterdiği bulunmuştur (Wang ve Zhao 2020). Sindiani ve arkadaşlarının çalışmasında (2020), öğrencilerin rahat hissedemediklerinden dolayı çevrim içi derslere katılmadıkları saptanmıştır. Çevrim içi eğitimin etkinliği ile ilgili üniversite öğrencilerinin $(n=126)$ görüşlerinin değerlendirildiğgi bir diğer çalışmada, öğrencilerin \%11.1’i elektronik ortamda iletişim kurarken rahat 
olmadığını ifade etmiştirler. Öğrencilerin \%8.7’si ise “öğrenmek için öğretim elemanıyla yüz yüze iletişim kurmak gereklidir” önermesine katılmamıştır (Adnan ve Kainat 2020). Karakuş ve arkadaşlarının (2020) çalışmasında, öğrenciler sınıf ortamındaki gibi yüz yüze görüşmeler yapılmadığından uzaktan eğitim sürecinde kendilerini daha rahat hissettikleri belirtmişlerdir. Pop ve arkadaşlarının (2011) çalışmasında, asenkron ses araçlarıyla iletişim kurmanın öğrencilerin seyirci önünde konuşma kaygısını azalttı̆̆ı bulunmuştur. Sosyal kaygısı olan bireyler ya kendilerine kaygı veren bu sosyal durumlardan kaçınmakta ya da belirgin bir sıkıntıya katlanarak bu durumları yaşamaktadırlar (Hofmann ve ark. 2010). Çalı̧̧ma sonuçları sosyal kaygısı olan üniversite öğrencileri için çevrim içi eğitim platformlarının güvenlik sağlayıcı bir ortam olduğunu göstermektedir. Sosyal etkileşim sayısı azaldıkça bireyin kaygısı ile baş etmek için kullandığı kaçınma davranışları güçlenecektir. Bu tür bir iyileşmenin kısa ömürlü olacağı, sosyal kaygısı olan bireylerin okullar yeniden açıldığında önemli zorluklarla karşılaşacakları belirtilmektedir (Morrissette 2021). Bu noktadan hareketle uzaktan eğitim alan üniversite öğrencilerinin sosyal kayg1 düzeylerinin belirlenmesinin önemli olduğu düşünülmektedir.

COVID-19 pandemisi nedeniyle üniversite öğrencilerinin yüz yüze olan sosyal ortamlara katılamaması sosyal kaygı düzeylerini etkileyebilir. Bu çalışma uzaktan eğitim alan üniversite ögrrencilerinin sosyal kaygı düzeylerinin belirlenmesi amacıyla tanımlayıcı türde bir araştırma olarak online yürütülmüştür. Çalışmanın hipotezleri sırasıyla şu şekilde belirlenmiştir. Uzaktan eğitim alan üniversite öğrencilerinin sosyal kayg1 düzeyleri yüksektir. Sınıf düzeylerine göre uzaktan eğitim alan üniversite öğrencilerinin sosyal kayg1 düzeyleri benzerdir. Uzaktan eğitim alan üniversite öğrencilerinin sosyal kaygısı ile olumsuz değerlendirilme korkusu arasında pozitif yönlü anlamlı bir ilişki vardır. Uzaktan eğitim sürecinde söz alarak derslere aktif katılım göstermeyen öğrenciler ile derslere aktif katılım gösteren öğrencilerin sosyal kaygı düzeyleri arasında fark vardır. Uzaktan eğitim sürecinde söz alıp koştuğu sırada kendini "sınıf ortamına göre daha kaygılı" hissettiğini ifade edenler ile "sınıf ortamına göre daha rahat" hissettiğini ifade edenlerin sosyal kaygı düzeyleri arasında fark vardır.

\section{Yöntem}

Çalışma, Ankara'da bir üniversitenin İnsan ve Toplum Bilimleri Fakültesi, Siyasal Bilgiler Fakültesi, İşletme Fakültesi, İslami İlimler Fakültesi ve Sağlık Bilimleri Fakültesi’nde 1. Sınıf, 2.sınıf, 3.sınıf ve 4.sınıf düzeyinde eğitim alan öğrencileriyle gerçekleştirilmiştir. Bu fakülteler belirlenirken 1. Sınıf, 2.sınıf, 3.sınıf ve 4.sınıf düzeyinde eğitim alan öğrencilerinin olması ve öğrencilerin senkron eğitim almaları göz önünde bulundurulmuştur.

\section{Örneklem}

Araştırmanın evrenini 2020-2021 eğitim öğretim yılı bahar döneminde öğrenim gören üniversite öğrencileri $(\mathrm{n}=6430)$ oluşturmuştur. Araştırmanın örnekleminin belirlenmesinde evreni belli örneklem hesaplama programı kullanılmış olup hesaplamada tahmini örneklem büyüklüğ̈̈ 363 olarak bulunmuştur (alfa=.05, güven aralığ1=\%95(\%45-\%55). Çalışmaya dahil edilme kriterleri katılımcının çalışmaya katılmayı kabul etmesi, 18 yaşından büyük olması, 2020-2021 eğitim öğretim yılı bahar döneminde aktif ders kayd1nın bulunması, lisans derslerine uzaktan eğitim platformları aracılığıyla katılıyor olması olarak; çalışmanın dışlama kriteri ise katılımcının çalışmaya katılmayı kabul etmemesi 
olarak belirlenmiştir. Bu kriterlerini karşılayan 670 öğrenci çalışmaya katılmıştır. Geriye dönük hesaplanan çalışmanın gücü \%100.0 bulunmuştur (Tip-1 hata=0.05, d=0.35), (G*Power 3.1.9.2 paket program1), (Lenhard ve Lenhard 2016).

\section{İşlem}

Araştırmanın yapılabilmesi için gerekli etik kurul izni Ankara Yıldırım Beyazıt Üniversitesi Sosyal ve Beşeri Bilimler Etik Kurulu'ndan (Tarih:16.02.2021, No:2021-17) alınmıştır. Çalışmaya katılan tüm öğrenciler online aydınlatılmış onam formunu okuyup onaylamışlardır. 2020-2021 eğitim öğretim yılı bahar döneminde öğrenim gören öğrencilere sosyodemografik veri formu, Liebowitz Sosyal Kaygı Ölçeği (LSKÖ) ve Olumsuz Değerlendirilme Korkusu Ölçeği (ODKÖ) uygulanmıştır. Bu formlar araştırmacılar tarafından "google formlar" aracılığıyla online uygulanabilir şekle dönüştürülerek çalışma öğrencilerin “@XXX.edu.tr” uzantılı kurumsal mail adreslerine gönderilmiştir. Tüm katılımcılara ulaşabilmek amacıyla fakülte temsilciliği yapan üniversite öğrencileriyle iletişime geçilerek çalışmanın amacı hakkında bilgi verilmiştir. Çalı̧̧ma bağlantısının öğrenci sosyal medya gruplarında (WhatsApp) paylaşılması sağlanmıştır. Bilgilendirilmiş onam formu, online formların ilk sayfasına eklenerek katılımcılara "çalışmaya katılmama veya katıldıktan sonra herhangi bir anda çalışmadan çıkma hakkına sahip” olduğu bilgisi verilmiştir. Veri toplama sürecine başlamadan önce, online anketin uygulanabilirliği araştırmacılar ve bu çalışmada yer almayan iki alan uzmanı tarafından kontrol edilmiştir.

Link paylaşımında, "yanıt düzenleme" ve "1 yanıtla sınırlandırma" özellikleri sistem üzerinden ayarlanmıştır. Veri kaybını önlemek amacıyla her bir sorunun tek bir seçeneğinin işaretlenerek doldurulması zorunlu olarak düzenlenmiştir. Online veri toplama aracı Bilgilendirilmiş Onam Formu (1 madde), Sosyodemografik veri formu (11 madde), Liebowitz Sosyal Kaygı Ölçeği (24 madde) ve Olumsuz Değerlendirilme Korkusu Ölçeği-Kısa Formu (11 madde) şelinde toplam 47 madde ve 4 web sayfindan oluşmaktadır. "Gizlilik ve Gizliliğin Korunması" ilkesi ve “Özerkliğe Saygı" ilkesini içeren etik ilkeler yerine getirilerek yürütülen çalışmamız, bireylerin gönüllülük esasına dayanmakta olup herhangi bir ders kredisi veya ücret ödemesi yapılmamıştır.

\section{Veri toplama araçlan}

Çalışma verileri sosyodemografik veri formu, Liebowitz Sosyal Kaygi Ölçeği (LSKÖ) ve Olumsuz Değerlendirilme Korkusu Ölçeği (ODKÖ) kullanılarak toplanmıştır.

\section{Sosyodemografik veri formu}

Çalışmada yaş, sınıf türü, bölümü, cinsiyet, günlük çalışma süresi, uzaktan eğitimde kamera açma ve konuşma durumu, sınıf ortamındaki yüz yüze eğitim koşulları ile sanal ortam koşullarının değerlendirilmesi gibi değişkenler hakkında bilgi edinmek amacıyla araştırmacılar tarafından literatür taranarak oluşturulmuştur. Sosyodemografik veri formu toplam 11 maddeden oluşmakta olup 4 açık uçlu, 7 kapalı uçlu sorular içermektedir. Bu tür sorular sorularak katılımcıların kapalı uçlu sorulara verdikleri yanıtların sebeplerinin araştırılmasını amaçlanmıştır.

\section{Liebowitz Sosyal Kaygı Ölçeği (LSKÖ)}

Sosyal durumlarla bağlantılı olarak kaygı ve kaçınmanın şiddetini belirlemek amacıyla Liebowitz ve arkadaşları (1987) tarafından geliştirilen ölçeğin Türkçe uyarlama 
çalışmaları Soykan ve arkadaşları (2003) tarafından yapılmıştır. Ölçek 24 maddeden oluşmakta olup kaygı ve kaçınma olmak üzere iki boyutu bulunmaktadır. Toplam ölçek puanı 48-192 arasında değişmektedir. Alınan puanın yükselmesi sosyal kaygı düzeyinin ve kaçınma davranı̧̧ının şiddetlendiğini göstermektedir. Kesme puanı ölçeğin alt boyutları için 25, ölçeğin toplam puanı için 50 olarak bulunmuştur (Soykan ve ark. 2003). Kayg1 puanı, sosyal etkileşim içeren ya da performans gerektiren durumlarda kalmaktan duyulan korku ya da kaygının şiddetini kapsamaktadır. Kaçınma puanı ise, sosyal etkileşim içeren ya da performans gerektiren durumlarda kalmaktan duyulan korku ya da kaygı sonucunda bu durumlardan kaçınma sıklığını kapsamaktadır. Ölçeğin, test tekrar test güvenirlik katsayısı $\mathrm{r}=.97$ bulunmuştur. Sosyal kaygı alt ölçeğinin Cronbach Alfa Değeri, $r=.96$, sosyal kaçınma alt ölçeğinin Cronbach Alfa Değeri, $r=.95$ bulunmuştur. Ölçeğin bütünün Cronbach Alfa Değeri, .98'dir. Ölçeğin Cronbach Alfa değeri .92 ila .81 arasındadır (Soykan ve ark. 2003). Bu çalışmada cronbach alfa katsayısı 0.95 olarak saptanmıştır.

\section{Olumsuz Değerlendirilme Korkusu Ölçeği-Kısa Formu (ODKÖ)}

Olumsuz Değerlendirilme Korkusu Ölçeği Kısa Formu-ODKÖ (The Brief Fear of Negative Evaluation Scale-BFNE) Leary (1983) tarafından bireyin başkaları tarafindan olumsuz ya da düşmanca değerlendirilmeye karşı toleransını ölçmeye yönelik olarak geliştirilmiş öz bildirim tarzı bir ölçektir. BFNE, korku ve endişe ifadelerini içeren 11 maddeden oluşmaktadır ve maddeler 5'li Likert tipi bir derecelendirmeye sahiptir. ODKÖ’ nün Türkçe uyarlaması Çetin ve arkadaşları (2010) tarafindan gerçekleştirilmiş olup güvenirlik ve ölçüt bağıntılı geçerlik çalışmaları tek faktörlü yapı üzerinden yürütülmüştür. Ölçeğin psikometrik özellikleri 325 üniversite öğrencisinden alınan veriler üzerinden gerçekleştirilmiştir. Ölçeğin iç tutarlılık katsayısı .84 olarak bulunmuştur. Olumsuz değerlendirilme korkusundan alınan puanların az olması, bireylerin olumsuz değerlendirilmekten korkmadığını ya da daha az korktuğunu göstermekte iken, ölçekten alınan puanların fazla olması bireylerin olumsuz değerlendirilme korkusunun fazla olduğunu göstermektedir (Çetin ve ark. 2010). Bu çalışmada Cronbach alfa katsayısı 0.91 olarak saptanmıştır.

\section{İstatistiksel analiz}

İstatistiksel analizler ve hesaplamalar için IBM SPSS Statistics 21.0 (IBM Corp. Released 2012. IBM SPSS Statisticsfor Windows, Version 21.0. Armonk, NY: IBM Corp.) programı kullanılmıştır. İstatistiksel anlamlılık düzeyi $\mathrm{p}<0.05$ olarak kabul edilmiştir. Yüzde 95 güven aralıklarının hesaplanmasında, sapması düzeltilmiş ve hızlandırılmış yüzdelik güven aralığı yöntemi (BCa) kullanılmıştır. Veriler araştırmacı tarafindan bilgisayar programına aktarılarak, bilgisayar ortamında analiz edilmiş ve istatistiksel yöntemlerinden; tanımlayıcı istatistikler (sayı, yüzde, ortalama, standart sapma), korelasyon testi, t testi ve tek yönlü varyans analizi (one-way Anova) testi kullanılmıştır. Liebowitz Sosyal Kaygi Ölçeği ve Olumsuz Değerlendirilme Korkusu Ölçeği-Kısa Formu bağımlı değişken; yaş, cinsiyet, sınıf düzeyi, uzaktan eğitimde derslere aktif katılım durumu, uzaktan eğitim sürecinde kayg1 yaşama durumu ise çalışmanın bağımsız değişkenlerini oluşturmaktadır. LSKÖ ile ODKÖ skorları arasındaki ilişkiyi belirlemek amacıyla korelasyon testi, sınıf düzeylerine göre LSKÖ ile ODKÖ skorları arasındaki farkı belirlemek amacyyla tek yönlü varyans analizi (one-way Anova) testi, LSKÖ ile ODKÖ skorlarının 
bağımsız ikili gruplarda farklılığının incelenmesinde ise t testi analizleri kullanılmıştır. Öğrencilerin açık uçlu sorulara vermiş olduğu yanıtlar araştırmacılar tarafından inlenmiştir. Özgünlüğün geçerliğini artırmak için çalışmaya katılan ve uzaktan eğitim sürecinde kaygı yaşadığını ifade eden bireylerin ifadelerinin bir kısmı doğrudan yazılarak araştırma bulgusu olarak sunulmuştur.

\section{Bulgular}

Çalışmamıza yaş ortalaması 20.77 2.77 olan 553 kadın (\%82.5), 117 (\%17.5) erkek olmak üzere toplam 670 üniversite öğrencisi katılmıştır. Öğrencilerin \%37.3'ünün (n= 250) 1. Sınıf olduğu ve \% 40.0'ının ( $n=268)$ günlük ortalama 1-2 saat aralığında ders çalıştığ1 bulunmuştur. Öğrencilerin üniversitede eğitim gördüğü bölümler Tablo 1'de sunulmuş olup, çalışmaya katılan öğrencilerin \%50.1'nin $(n=336)$ Sağlık Bilimleri Fakültesi’nde eğitim gördüğü saptanmıştır. Öğrencilerin \%14.6’sı $(n=98)$ daha önce bir psikiyatrik tedavi aldığını belirtmiştir (Tablo 1).

Tablo 1. Öğrencilerin tanımlayıcı özelliklerinin dağılımı $(n=670)$

\begin{tabular}{|c|c|c|}
\hline Tanımlayıcı Özellik & $\mathbf{n}$ & $\%$ \\
\hline Sağlık Bilimleri Fakültesi & 336 & 50.1 \\
\hline Hemşirelik & 152 & 22.7 \\
\hline Beslenme ve Diyetetik & 86 & 12.8 \\
\hline Sosyal Hizmet & 59 & 8.8 \\
\hline Dil ve Konuşma Terapisi & 19 & 2.8 \\
\hline Odyoloji & 10 & 1.5 \\
\hline Çocuk Gelişimi & 7 & 1.0 \\
\hline Fizyoterapi ve Rehabilitasyon & 3 & 0.4 \\
\hline İnsan ve Toplum Bilimleri & 305 & 45.5 \\
\hline Bilgi ve Belge Yönetimi & 99 & 14.8 \\
\hline Psikoloji & 78 & 11.6 \\
\hline Türk Dili ve Edebiyatı & 32 & 4.8 \\
\hline Sosyoloji & 29 & 4.3 \\
\hline Mütercim Tercümanlık & 29 & 4.3 \\
\hline Tarih & 24 & 3.6 \\
\hline Felsefe & 14 & 2.1 \\
\hline İşletme Fakültesi & 13 & 1.9 \\
\hline Uluslararası Ticaret ve İsletmecilik & 9 & 1.3 \\
\hline Yönetim Bilişim Sistemleri & 4 & 0.6 \\
\hline Siyasal Bilgiler Fakültesi & 8 & 1.2 \\
\hline Siyaset Bilimi ve Kamu Yönetimi & 5 & 0.7 \\
\hline Uluslarası Illişkiler & 2 & 0.3 \\
\hline Maliye & 1 & 0.1 \\
\hline İslami Ilimler Fakültesi & 8 & 1.2 \\
\hline İslami Ilimler & 8 & 1.2 \\
\hline \multicolumn{3}{|l|}{ Sinıf düzeyi } \\
\hline Hazırlık sınıfı & 37 & 5.5 \\
\hline Sinif & 250 & 37.3 \\
\hline Sinif & 169 & 25.2 \\
\hline Sinif & 126 & 18.8 \\
\hline Sinif & 88 & 13.1 \\
\hline \multicolumn{3}{|l|}{ Ders çalışma süresi } \\
\hline 1 saatten az & 173 & 25.8 \\
\hline
\end{tabular}




\begin{tabular}{lcc}
\hline 1-2 saat & 268 & 40.0 \\
\hline 3-4 saat & 180 & 26.9 \\
\hline 5-6 saat & 39 & 5.8 \\
\hline 7 saat ve üzeri & 10 & 1.5 \\
\hline Psikiyatrik tedavi öyküsü & & \\
\hline Evet & 98 & 14.6 \\
\hline Hayır & 572 & 85.4 \\
\hline Uzaktan eğitimde derslere aktif katılım durumu & & \\
\hline Evet & 435 & 64.9 \\
\hline Hayır & 235 & 35.1 \\
\hline
\end{tabular}

Öğrencilerin LSKÖ toplam puanı $94.10 \pm .95$, LSKÖ’nin kayg1 alt boyutu puan1 $47.84 \pm .49$, kaçınma alt boyutu $46.26 \pm .48$ olarak bulunmuştur. ODKÖ toplam puanı ise $30.38 \pm 9.07$ bulunmuştur (Tablo 2).

Tablo 2. Öğrencilerin LSKÖ ve ODKÖ ölçeklerinden aldıkları puanların dağııımı ( $n=670)$.

\begin{tabular}{lcc}
\hline Ölçekler & Ort \pm SS & Min-Max \\
\hline ODKÖ & $30.38 \pm 9.07$ & $11.0-55.0$ \\
\hline LSKÖ Kaygı & $47.84 \pm 12.89$ & $24.0-96.0$ \\
\hline LSKÖ Ką̧ınma & $46.26 \pm 12.55$ & $24.0-93.0$ \\
\hline LSKÖ Toplam & $94.10 \pm 24.71$ & $48.0-186.0$ \\
\hline
\end{tabular}

Ort: Ortalama, SS: standart sapma, LSKÖ:Liebowitz Sosyal Kaygı Ölçeği; ODKÖ:Olumsuz Değerlendirilme Korkusu Ölçeği-Kısa Formu

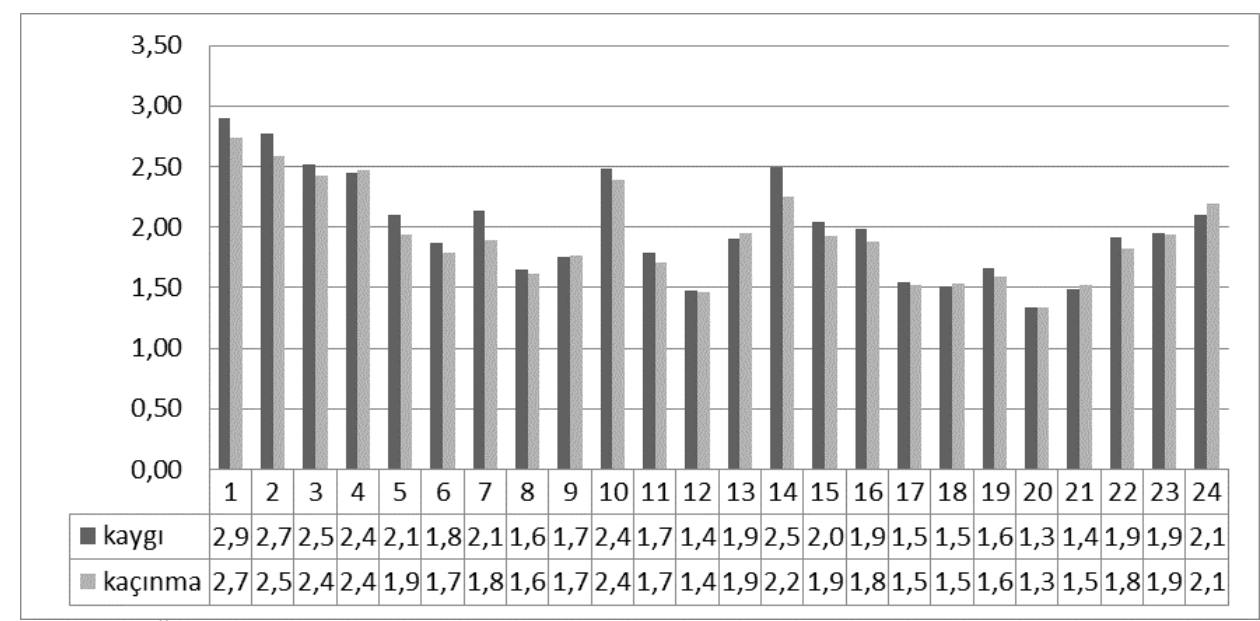

\section{Şekil 1. LSKÖ'deki her bir sorunun ortalama kaygı ve kaçınma seviyesi}

*LSKÖ:Liebowitz Sosyal Kaygı Ölçeği maddeleri (1-24)

Ö ğrencilerin en çok kayg1 yaşadığı sosyal durumlar: önceden hazırlanmaksızın bir toplantıda kalkıp konuşmak (Ort= 2.90, SS= .90), seyirci önünde hareket, gösteri ya da konuşma yapmak (Ort= 2.77, $\mathrm{SS}=.91$ ), dikkatleri üzerinde toplamak (Ort= 2.51, SS= .92), romantik veya cinsel bir ilişki kurmak amacıyla birisiyle tanışmaya çalışmak (Ort= 2.44, SS=1.00), bir gruba önceden hazırlanmış sözlü bilgi sunmak (Ort=2.10, SS= .88), kendisinden daha yetkili biriyle konuşmak (Ort= 2.14, $\mathrm{SS}=.87$ ), gözlendiği sırada çalışmak (Ort= 2.49, $\mathrm{SS}=.96)$, yetenek, beceri ya da bilginin sınanması (Ort= 2.50, SS= .92), gözlendiği sırada yazı yazmak (Ort= 2.04, SS= .95) ve umumi tuvalette idrar yapmak $(\mathrm{Ort}=2.10, \mathrm{SS}=1.10)$ olarak bulunmuştur (Şekil 1). Öğrencilerin LSKÖ ile 
ODKÖ skorları arasında istatistiksel olarak anlamlı bir ilişki bulunmamıştır $(r=0.04, p$ > $0.05, \% 95 \mathrm{BCa}[-0.03,0.12])$.

Sınıf düzeylerine göre öğrencilerin LSKÖ ve ODKÖ puan ortalamaları benzerdir (F $(4,665)=0.923, \mathrm{p}=0.45, \% 95 \mathrm{BCa}[92.32,95.85] ; \mathrm{F}(4,665)=1.92, \mathrm{p}=0.10, \% 95 \mathrm{BCa}$ [29.68, 31.12]). Öğrencilerin \%64.9'unun $(n=435)$ uzaktan eğitim sürecinde söz alarak derslere aktif katıldığ1 bulunmuştur. Uzaktan eğitim sürecinde söz alarak derslere aktif katılım göstermeyen öğrencilerin derslere aktif katılım gösteren öğrencilere göre LSKÖ ve ODKÖ puanlarının daha yüksek olduğu bulunmuştur ancak bu fark istatistiksel olarak anlamlı değildir $(\mathrm{t}(668)=-1.03, \mathrm{p}=0.30, \% 95 \mathrm{BCa}[-6.13,1.79] ; \mathrm{t}(668)=-0.56, \mathrm{p}=$ $0.57, \% 95 \mathrm{BCa}[-1.78,0.98]),($ Tablo 3).

Öğrencilerin \%31.6’s1 (n= 212) uzaktan eğitim sürecinde söz alıp koştuğu sırada kendini "sınıf ortamına göre daha kayg1lı" hissettiğini, \%27.9'u (n=187) "sınıf ortamına göre daha rahat” hissettiğini belirtmiştir. Öğrencilerin uzaktan eğitim sürecinde yaşadığ kayg1 durumlarına göre LSKÖ ve ODKÖ skorları arasındaki fark istatistiksel olarak benzer bulunmuştur $(\mathrm{F}(3,666)=0.819, \mathrm{p}=0.48, \% 95 \mathrm{BCa}[92.18,95.95] ; \mathrm{F}(3,666)=$ 1.88, p=0.13, \%95 BCa [29.75, 31.04]), (Tablo 3).

Tablo 3. Belirli değişkenlere göre LSKÖ ve ODKÖ dağılımı $(n=670)$

\begin{tabular}{|c|c|c|c|c|}
\hline \multirow[t]{2}{*}{ Değişkenler } & ODKÖ & LSKÖ kaygı & LSKÖ kaçınma & $\begin{array}{l}\text { LSKÖ } \\
\text { toplam }\end{array}$ \\
\hline & Ort. $\pm S S$ & Ort. $\pm S S$ & Ort. $\pm S S$ & Ort. $\pm S S$ \\
\hline \multicolumn{5}{|l|}{ Sinıf Düzeyi } \\
\hline Hazırlık & $27.83 \pm 8.77$ & $44.57 \pm 11.22$ & $43.35 \pm 10.36$ & $87.92 \pm 20.99$ \\
\hline 1.sınıf & $30.49 \pm 8.51$ & $47.64 \pm 12.09$ & $46.17 \pm 12.05$ & $93.81 \pm 23.62$ \\
\hline 2. sinif & $31.56 \pm 10.04$ & $48.14 \pm 13.61$ & $47.01 \pm 13.45$ & $95.15 \pm 26.45$ \\
\hline 3.sinif & $30.26 \pm 8.27$ & $47.93 \pm 13.67$ & $45.38 \pm 13.04$ & $93.31 \pm 25.41$ \\
\hline 4.sinif & $29.07 \pm 8.90$ & $49.05 \pm 13.20$ & $47.57 \pm 12.27$ & $96.61 \pm 24.72$ \\
\hline $\mathrm{F}$ & 1.929 & .827 & 1.044 & .923 \\
\hline $\mathrm{pa}$ & .104 & .508 & .384 & .450 \\
\hline \multicolumn{5}{|l|}{ Kaygı Durumu } \\
\hline $\begin{array}{l}\text { Sınıf ortamında olduğu gibi } \\
\text { kaygılı hissettim }\end{array}$ & $31.02 \pm 8.59$ & $46.73 \pm 13.83$ & $45.28 \pm 14.09$ & $92.01 \pm 27.59$ \\
\hline $\begin{array}{l}\text { Sınıf ortamına göre daha kaygılı } \\
\text { hissettim }\end{array}$ & $29.23 \pm 9.83$ & $48.51 \pm 11.87$ & $47.47 \pm 12.07$ & $95.98 \pm 23.34$ \\
\hline $\begin{array}{l}\text { Sinıf ortamına göre daha rahat } \\
\text { hissettim }\end{array}$ & $31.25 \pm 8.86$ & $48.17 \pm 13.68$ & $46.14 \pm 12.85$ & $94.30 \pm 25.42$ \\
\hline $\begin{array}{l}\text { Duygu durumumda değişim } \\
\text { olmadı }\end{array}$ & $30.50 \pm 8.48$ & $47.28 \pm 12.70$ & $45.47 \pm 11.86$ & $92.76 \pm 23.83$ \\
\hline $\mathrm{F}$ & 1.888 & .581 & 1.090 & .819 \\
\hline $\mathrm{pa}$ & .130 & .627 & .353 & .484 \\
\hline \multicolumn{5}{|l|}{ Derslere aktif katılım durumu } \\
\hline Evet & $30.24 \pm 9.10$ & $47.51 \pm 12.97$ & $45.86 \pm 12.65$ & $93.37 \pm 24.79$ \\
\hline Hayır & $30.65 \pm 9.01$ & $48.43 \pm 12.74$ & $47.01 \pm 12.37$ & $95.44 \pm 24.55$ \\
\hline $\mathrm{t}$ & -.560 & -.876 & -.1 .130 & -.1 .031 \\
\hline $\mathrm{P}^{\mathrm{b}}$ & .576 & .381 & .259 & .303 \\
\hline
\end{tabular}

ane-way Anova, ${ }^{b t}$ testi, $\mathrm{p}<.05$, LSKÖ:Liebowitz Sosyal Kaygı Ölçeği; ODKÖ:Olumsuz Değerlendirilme Korkusu Ölçeği-Kısa Formu

Öğrencilerin uzaktan eğitimi tercih etme nedenleri incelendiğinde "kişisel gelişime daha çok zaman kalması", "salgın nedeniyle güvende olunması", "ders çalışırken daha rahat bir ortamın olması", "dersleri tekrarlı izleme fırsatının olması" gibi çeşitli 
kategoride toplanan yanıtlar elde edilmiştir. Ancak sosyal kaygisı olanların sanal sınıf ortamını güvenlik sağlayıcı bir ortam olarak değerlendirdiği söylenebilir.

K1:"Çevrim içi (Sanal ortam), sınıf ortamından daha rahat bir ortam geliyor. Çünkü kendimizi ifade ederken yanımızda kimse olmadığı için heyecanlanma durumu olmuyor."

K2:"Sanal ortamı tercih ederim. Beni görmedikleri için daha rahattım."

K3:"Sanal ortamı tercih ederim. Çünkü sınıf ortamındayken yaşadığım anksiyeteyi eğitimcinin farketmesi beni olumsuz etkiler. Ama sanal ortamda anksiyete yaşadı̆ı̆mda eğitimci farketmeden anksiyetemi kontrol altına alabilirim."

K4:"Sanal ortamı tercih ederim. Çünkü bir şey söylerken veya sunumunu anlatırken sanal ortamda diğerlerini görmüyorsun, daha rahat oluyor insan açıkçası."

K5:"Sanal ortami tercih ederim. Okul ortaminda daha fazla stres yassıorum."

K6:"Sana ortamı tercih ederim çünkü, kendimi daha güvende hissediyorum."

K7:"iletişim açııından sinnf ortamınn isterim fakat sınıfta daha anksiyeteli olabiliyorum. Online olduğunda chatten yazarken daha iyi hissediyorum."

K8: "Sanal ortam daha iyi. Kendimi sunum yaparken ve derse katılımda daha rahat hissettim."

K9"Sanal ortam daha endişesiz."

K10:"Sanal ortamı çünkü; söz aldıktan sonra göz teması kurmamıza veya mimikleri kullanmamıza gerek kalmıyor. Bu da daha rahat bir şekilde kendimizi ifade etmemizi sağlyor."

K11:"Sanal ortam kendini daha rahat ifade edebilirsin."

K12:"Uzaktan eğitim sürecinde kamera açamadığım için kendimi konuşurken daha rahat hissettim. Bu yüzden sorulan sorulara daha rahat cevap verdim."

K13: "Sanal ortamı tercih ederim. Görünmemek beni daha rahat kiliyor."

K14:"Sanal ortamı, çünkü kimsenin yanında olmadığını ve seni görmeyeceklerini bilmek güzel."

K15: "Sanal ortamı tercih ederim, kendimi daha az baskı altında hissediyorum ve düşüncelerimi ifade ederken zorlanmıyorum."

K16:"Sanal ortamı tercih ederim. Kamera açmak zorunlu olmadığı takdirde kimliğimiz belli olmuyor bu da daha az stresli hissetmemizeneden oluyor."

\section{Tartışma}

COVID-19 (SARS-CoV-2) pandemisi nedeniyle eğitimlerine uzaktan eğitim ile devam eden üniversite öğrencilerinin sosyal kaygı düzeylerinin belirlenmesi amacıyla yürütülen çalışmamızda öğrencilerin sosyal kaygı ile olumsuz değerlendirilme korkusu düzeylerinin yüksek olduğu ve uzaktan eğitimi kaygı ile baş etmede olumlu bir ortam olarak değerlendirdikleri sonucuna ulaşılmıştır. Hayatın doğal akışında yaşanan durumlar, güvenlik sağlayıcı davranış olarak işlev görmüştür.

Üniversite öğrencilerinin $(\% 17,6)$ psikolojik sağlık sorunları nedeniyle geleneksel yüz yüze eğitim yerine çevrim içi eğitimi tercih ettikleri belirtilmektedir (Drange ve Wyk 2019). Bu sonuç, psikolojik sorunların çevrim içi eğitimle ilişkisini araştırmaya değer olduğunu göstermektedir. Pandeminin sosyal kaygısı olan bireyler için tehdit teşkil ettiği belirtilmekte olup sosyal kaygının, pandemi sırasında olumsuz değerlendirme korkusundaki artı̧̧1 yordadığ 1 bulunmuştur (Ho ve Moscovitch 2021). Olumsuz değerlendirme korkusu, öğrencilerin çevrim içi öğrenme ortamındaki etkileşimleri sırasında başkaları tarafından yanlış anlaşılma ve yargılanma olasılığına ilişkin olumsuz duygu, düşünce, korku ve endişe düzeylerini içerebilmektedir. Wang ve Zhao'nın (2020) çalışmasında, çevrim içi öğrenme ile bağlantılı olarak üniversite öğrencilerinin kaygıları incelenmiştir. Üniversite öğrencilerinin genel popülasyona göre daha yüksek düzeyde kaygıya sahip olduğu bulunmuştur (Wang ve Zhao 2020). Drange ve Wyk'nın (2019) çalışmasına katılan 264 üniversite öğrencinin \%70'inden fazlasının sosyal kaygı skorlarının LSKÖ’nin kesme puanının üzerinde olduğu bulunmuştur. Kovid-19 salgınının üniversite öğrencilerini daha kaygılı hale getirdiği belirtilmekte olup $\mathrm{Ma}$ (2021)'nın çalışmasında üniversite öğrencilerinin sosyal kaygı ile yılmazlık düzeyleri 
arasında negatif yönlü anlamlı bir ilişki saptanmıştır. Thompson ve arkadaşlarının (2021) çalışmasında COVID-19 pandemisinin başlamasından sonra sosyal kaygı belirtilerinin arttığ1 bulunmuştur.

Çalı̧̧mamızda üniversite öğrencilerinin sosyal kaygı düzeylerinin tüm sınıf düzeylerinde benzer olduğu bulunmuştur. Ghezelbash ve arkadaşlarının (2015) çalışmasında, üniversite öğrencilerinin sosyal kaygı puan ortalamaları ile sınıf düzeyleri arasında anlamlı bir fark saptanmamıştır. Sharma ve Sharma'nın (2015) çalışmasında kaygı düzeyi ile sınıf düzeyleri arasında fark bulunmamıştır. Gültekin ve Dereboy (2011) çalışmalarında, öğrencilerin eğitim gördüğü bölüm, sınıf ile sosyal kayg1 görülme sıklığı arasında istatistiksel olarak anlamlı bir fark bulunmamıştır. Bu çalışma sonuçları öğrencilerin kaygısının eğitim öğretim süreci, eğitim yöntemi, teorik bilgi ve klinik deneyim gibi faktörlerle değişmediğini göstermektedir. Bu nedenle, sosyal kaygı farklı dinamikleri olan çevrimiçi öğrenme bağlamında özel olarak ele alınmalıdır. Öğrenciler eğitim ortamında zamanında fark edilmeli ve gerekli müdahaleler yapılarak, hem akademik hem de sosyal yaşamlarına hazırlanmalıdır.

Sosyal kaygısı olan üniversite öğrencilerini en sık kaygılandıran sosyal durumlar dikkatleri üzerinde toplamak, yetenek, beceri ya da bilginin sinanması, seyirci önünde hareket, gösteri ya da konuşma yapmak, romantik veya cinsel bir ilişki kurmak amaciyla birisiyle tanışmaya çalışmak, gözlendiği sırada çalışmak, önceden hazırlanmaksızın bir toplantıda kalkıp konuşmak, fikir ayrılığını ifade etmek, kalabalık bir odaya girmek şeklinde bulunmuştur (Bella ve Omigbodun 2009, Gultekin ve Dereboy 2011, Russell ve Topham 2012). Üniversite öğrencilerinin sosyal kaygı yaşadığ1 durumlar, pandemi sürecinde yapılan çalışma sonuçları ile benzerlik göstermektedir. Karakuş ve arkadaşları (2020) üniversite öğrencilerinin uzaktan eğitime yönelik görüşlerini incelemişlerdir. Öğrenciler sınıf ortamında grup önünde konuşmak, öğretmen ve diğer arkadaşlarının olumsuz değerlendirmesi gibi durumlar hakkında kaygı yaşadıklarını belirtmişlerdir (Karakuş ve ark. 2020). Drange ve Wyk'nın (2019) çalışmasında üniversite öğrencilerini en çok kaygılandıran durum seyirci önünde gösteri ya da konuşma yapmak olarak bulunmuştur. Uzunboylu ve Tuncay (2010) çalışmasında uzaktan eğitim alan öğrencileri en çok kaygılandıran durumlar seyirci önünde konuşmak ve dikkatleri üzerinde toplamak şeklindedir. Çalışma sonuçlarından elde edilen ve üniversite öğrencilerinin kaygılanmasına yol açan sosyal durumlar çalışma bulgularımız ile benzer özellik göstermektedir.

Sosyal kaygılı bireyler başkalarıyla bağlantı kurmak için sosyal fırsatlardan kaçınma eğilimi göstermektedirler (Heeren ve McNally 2018). Pandemi koşulları, sosyal kaygısı olan kişiler için psikolojik tedavinin maruz kalmayı teşvik edeceği durumlardan kaçınmak için olumlu pekiştirme sağlamaktadır (Morrissette 2020). Ayrıca, pandemi sırasındaki sosyal etkileşimlerin doğası, kendini gizleme konusunda doğal olarak daha fazla firsatlar sunabilmektedir. Bunun nedeni ise pandemi sırasında gerçek sosyal etkileşim için firsatların azalması ve pandeminin bir sonucu olarak ortaya çıkan sosyal olarak tehdit edici yeni durumlarla yüzleşmek olarak açıklanabilmektedir. Miers ve arkadaşlarının (2020) çalışmasında, sosyal kaygının çevrim içi kaçınma davranışlarını yordadığı bulunmuştur. Karakuş ve arkadaşlarının (2020) çalışmasında üniversite öğrencileri "Sınıf önünde konuşma yapmada utanan insanlar uzaktan eğitimde daha rahat konuşabiliyorlar.”şeklindeki görüşlerini açıklamışlardır (Karakuş ve ark. 2020). Bir diğer çalışmada uzaktan eğitim sırasında öğrencilerin kitaba yazılar yazıp resimler çizmesi ve öğretmenden gizlenmeleri kaçınma davranışları olarak belirtilmektedir (Uzunboylu ve 
Tuncay 2010). Zheng ve arkadaşlarının (2020) çalışmasında ise psikolojik mesafe ile kayg1 arasında negatif yönlü bir ilişki olduğu bulunmuştur. Pandemi nedeniyle psikolojik mesafenin, pandemi şiddeti ile sosyal kaygı arasındaki ilişkide aracı etkisinin olduğu kanıtlanmış olup karantinanın pandeminin zararlı etkilerine karşı sosyal kaygısı olanları koruduğu belirtilmektedir (Zheng ve ark. 2020). Uzaktan eğitimin öğrenci görüşleriyle değerlendirildiği çalışmalarda ise öğrencilerin çevrim içi eğitimde akranlarıyla daha iyi etkileşim sağladıkları ve öğrenmek için yüz yüze iletişime gerek olmadığ1 şeklinde açıklamaları sosyal kaygı ile baş etmede kullandıkları bir kaçınma davranışı olabilir (Adnan ve Kainat 2020, Sindiani ve ark. 2020). Çalışmamızda öğrencilerin çevrim içi eğitimde daha rahat hissetiklerini ifade etmeleri, yüz yüze eğitim yerine çevrim içi eğitimi tercih etmeleri, kameralarını açmamaları ve sorularını sobhet kutusuna yazmaları kaçınma davranışlarına örnek olarak verilebilir. Kaçınma davranışları bireyin korkulan sonucun gerçekleşmesinin muhtemel olmadığını keşfetmesini engellemekte ve kayg1 semptomlarının devam etmesine neden olmaktadır.

Araştırmanın yalnızca bir üniversitenin belirli bölümlerinde öğrenim gören öğrenciler ile yürütülmüş olması, veri toplama formlarının elektronik ortamda uygulanması, öğrenciler ile iletişimin yüz yüze sağlanamaması bu çalışmanın önemli kısıtlılıklarını oluşturmaktadır.

\section{Sonuç}

Çalışmamızda üniversite öğrencilerinin pandemi sürecindeki sosyal kaygı düzeyi ve olumsuz değerlendirilme korkusu incelenmiştir. Öğrencilerin sosyal kayg1 düzeyleri ve olumsuz değerlendirilme korkusu yüksek bulunmuş olup kaygısı yüksek olan öğrencilerin çevrim içi eğitimi kaygı ile baş etmede olumlu bir ortam olarak değerlendirdikleri sonucuna ulaşılmıştır. Bu durum kaygının azaltılmasında etkili bir yöntem olmayıp sosyal kaygılı bireyin kayg1 düzeyinin artmasına ve yüz yüze eğitime geçildiğinde sınıf ortamında meydana gelebilecek olan gerçek sosyal durumlarda zorlukların yaşanmasına yol açabilir. Yen ve arkadaşları (2012) gerçek yaşam ve çevrimiçi etkileşimlerde sosyal kaygının şiddetini karşılaştırmış ve çevrimiçi etkileşimlerde sosyal kaygının azaldığını tespit etmişlerdir. Öğgrencilerin pandemi öncesi ve sonrası sosyal kaygı düzeylerinin belirlenmesi ve öğrencilerin sosyal kaygılarıyla baş etmede akran gruplarıyla çevrim içi toplantılara ve/ veya etkinliklere aktif katılması, eğitim öğretim platformlarında sürdürülen canlı derslere aktif katılabilmesi için kamera ve mikrofon kullanımının desteklenmesi gibi çevrim içi sosyal durumlara maruziyetlerinin artırılması önerilmektedir.

\section{Kaynaklar}

Adnan M, Anwar K (2020) Online learning amid the COVID-19 pandemic:Students' perspectives. Journal of Pedagogical Sociology and Psychology, 2:45-51.

Bella TT, Omigbodun 00 (2009) Social phobia in Nigerian university students:Prevalence, correlates and co-morbidity. Soc Psychiatry Psychiatr Epidemiol, 44:458-463.

Carruthers SE, Warnock-Parkes EL, Clark DM (2019) Accessing social media:Help or hindrance for people with social anxiety? J Exp Psychopathol, 10:1-11.

Cetin B, Doğan T, Sapmaz F (2010) Olumsuz Değerlendirilme Korkusu Ölçeği Kısa Formu'nun Türkçe uyarlaması:Geçerlik ve güvenirlik çalışması. Education in Science, 35:206-216.

Clark DA, Beck AT (2010) Cognitive Therapy of Anxiety Disorders: Science And Practice. New York, Guilford Press. 
Courtney D, Watson P, Battaglia M, Mulsant BH, Szatmari P (2020) COVID-19 impacts on child and youth anxiety and depression:Challenges and opportunities. Can J Psychiatry, 65:688-691.

Drange T, Van Wyk N (2019) Social anxiety-an increasing challenge for educators. EDULEARN19 Proceedings, 6045-6051.

Ghezelbash S, Rahmani F, Peyrovi H, Imamloo M (2015) Social anxiety in nursing students of tehran universities of medical sciences. Res Dev Med Educ, 4:85-90,

Groarke JM, Berry E, Graham-Wisener L, McKenna-Plumley PE, McGlinchey E, Armour C (2020) Loneliness in the UK during the COVID-19 pandemic:Cross-sectional results from the COVID-19 psychological wellbeing study. PLoS One, 15:e0239698.

Gultekin BK, Dereboy IF (2011) The prevalence of social phobia, and its impact on quality of life, academic achievement, and identity formation in university students. Turk Psikiyatri Derg, 22:150-158.

Heeren A, McNally RJ (2018) Social anxiety disorder as a densely interconnected network of fear and avoidance for social situations. Cogn Ther Res, 42:103-113.

Ho J, Moscovitch DA (2021) The moderating effects of reported pre-pandemic social anxiety, symptom impairment, and current stressors on mental health and affiliative adjustment during the first wave of the COVID-19 pandemic. Anxiety Stress Coping, doi:10.1080/10615806.2021.1946518.

Hofmann SG, DiBartolo PM (2010) Social Anxiety: Clinical, Developmental, and Social Perspectives, 2nd ed. London, Academic Press.

Karakuş N, Ucuzsatar N, Karacaoğlu MÖ, Esendemir N, Bayraktar D (2020) Türkçe öğretmeni adaylarının uzaktan eğitime yönelik görüşleri. RumeliDE Dil ve Edebiyat Araştırmaları Dergisi, 19:220-241.

Khalil R, Mansour AE, Fadda WA, Almisnid K, Aldamegh M, Al-Nafeesah A et al. (2020) The sudden transition to synchronized online learning during the COVID-19 pandemic in Saudi Arabia:a qualitative study exploring medical students' perspectives. BMC Med Educ, 20:285.

Kim DH (2018) 'How do you feel about a disease?' The effect of psychological distance towards a disease on health communication. Int J Advert, 38:1-15.

Kingsbury M, Coplan RJ (2016) RU mad @ me? Social anxiety and interpretation of ambiguous text messages. Comput Hum Behav, 54:368-379.

Lenhard W, Lenhard A (2016) Calculation of Effect Sizes. https://www.psychometrica.de/effect_size.html. Dettelbach (Germany): Psychometrica. doi: 10.13140/RG.2.2.17823.92329 (Retrieved October 01, 2021).

Liberman N, Trope Y (2014) Traversing psychological distance. Trends Cogn Sci, 18:364-369.

Loades ME, Chatburn E, Higson-Sweeney N, Reynolds S, Shafran R, Brigden A et al. (2020) Rapid systematic review:The Impact of social isolation and loneliness on the mental health of children and adolescents in the context of COVID-19. J Am Acad Child Adolesc Psychiatry, 59:1218-1239.e3.

Ma A (2021) Coping with social anxiety and maintaining resilience in university of minnesota students during the COVID-19 pandemic a correlational approach. Psychology Sociology \& Education, 4:1-17.

Miers AC, Sumter SR, Clark DM, Leigh E (2020) Interpretation bias in online and offline social environments and associations with social anxiety, peer victimization, and avoidance behavior. Cogn Ther Res, 44:820-833.

Morris TL, Ale CM (2011) Social anxiety. In Handbook of Child and Adolescent Anxiety Disorders (Eds D McKay, EA Stroch):289-303. New York, Springer.

Morrissette M (2021) School closures and social anxiety during the COVID-19 Pandemic. J Am Acad Child Adolesc Psychiatry, 60:67.

Pop A, Tomuletiu EA, David D (2011) EFL speaking communication with asynchronous voice tools for adult students. Procedia Soc Behav Sci, 15:1199-1203.

Rubin GJ, Amlôt R, Page LA, Wessely S (2009) Public perceptions, anxiety, and behaviour change in relation to the swine flu outbreak: Cross sectional telephone survey. BMJ, 339:b2651.

Russell G,Topham P (2012) The impact of social anxiety on student learning and well-being in higher education. J Ment Health, 21:375-385.

Sharma R, Sharma P (2015) A correlational study to assess the relation of anxiety and social phobia with academic performance of students in a selected nursing college Ludhiana, Punjab. Int. J. Nurs. Educ, 7:26. 
Sindiani AM, Obeidat N, Alshdaifat E, Elsalem L, Alwani MM, Rawashdeh H et al. (2020) Distance education during the COVID-19 outbreak: A cross-sectional study among medical students in North of Jordan. Ann Med Surg (Lond), 59:186-194.

Soykan C, Ozguven HD,Gencoz T (2003) Liebowitz social anxiety scale: The Turkish version. Psychol Rep, 93:1059-69.

Thompson C, Mancebo MC, Moitra E (2021) Changes in social anxiety symptoms and loneliness after increased isolation during the COVID-19 pandemic. Psychiatry Res, 298:113834.

Türkçapar MH (2018) Bilişsel Terapi: Temel ilkeler ve uygulama, 11. Baskı. Ankara, HYB Basım Yayın.

Uzunboylu H, Tuncay N (2010) Anxiety and resistancen In distance learning. Cypriot Journal Of Educational Sciences, 5:142-150.

Valkenburg PM, Peter J, Walther JB (2016) Media effects: Theory and research. Annu Rev Psychol, 67:315-338.

Walther JB (2011) Theories of computer-mediated communication and interpersonal relations. The Handbook of Interpersonal Communication, 4:443-479.

Wang C, Zhao H (2020) The impact of COVID-19 on anxiety in chinese university students. Front Psychol, 11:1168.

Weidman AC, Fernandez KC, Levinson CA, Augustine AA, Larsen RJ, Rodebaugh TL (2012) Compensatory internet use among individuals higher in social anxiety and its implications for well-being. Pers Individ Dif, 53:191-195,

Yen JY, Yen CF, Chen CS, Wang PW, Chang YH, Ko CH (2012) Social anxiety in online and real-life interaction and their associated factors. Cyberpsychol Behav Soc Netw, 15:7-12.

Zheng L, Miao M, Lim J, Li M, Nie S, Zhang X (2020) Is lockdown bad for social anxiety in COVID-19 regions?: A national study in the SOR perspective. Int J Environ Res Public Health, 17:4561..

Yazarların Katkıları: Yazarlar çalışmaya önemli bir bilimsel katkı sağladıklarını ve makalenin hazırlanmasında veya gözden geçirilmesinde yardımcı olduklarını kabul etmişlerdir.

Danışman Değerlendirmesi: Dış bağımsız

Etik Onay: Araştırma için Ankara Yıldırım Beyazıt Üniversitesi Sosyal ve Beşeri Bilimler Etik Kurulundan onay alınmıştır. Tüm katılımcılar aydınlatılmış onam vermişlerdir.

Çıkar Çatışması: Yazarlar çıkar çatışması bildirmemiştir.

Finansal Destek: Yazarlar bu çalışma için finansal destek almadıklarını beyan etmişlerdir.

Authors Contributions. Authors attest that they have made an important scientific contribution to the study and have assisted with the drafting or revising of the manuscript.

Peer-review: Externally peer-reviewed.

Ethical Approval: Ethical approval was obtained from Ankara Yıldırım Beyazıt University Social and Human Sciences Studies Ethics Committee for the study. All participants gave informed consent.

Conflict of Interest: No conflict of interest was declared by the authors.

Financial Disclosure: The authors declared that this study has received no financial support. 